\title{
Understanding what controls the spatial distribution of fish populations using a multi-model approach
}

\author{
Benjamin Planqué ${ }^{1,{ }^{*}}$, Christophe Loots ${ }^{2}$, Pierre Petitgas ${ }^{3}$, Ulf Lindstrøm ${ }^{1}$, Sandrine Vaz ${ }^{2}$
}

${ }^{1}$ Institute of Marine Research, Postboks 6404, 9294 Tromsø, Norway

${ }^{2}$ Institut Français de Recherche pour l'Exploitation de la Mer, Laboratoire Ressources Halieutiques, 150 quai Gambetta, BP 699, 62321 Boulogne-sur-Mer, France

${ }^{3}$ Institut Français de Recherche pour l'Exploitation de la Mer, Département Ecologie et Modèles pour l'Halieutique, rue de l'île d'Yeu, B.P. 21105, 44311 Nantes Cedex 03, France

*: Corresponding author : B. Planqué, email address : benjamin.planque@imr.no

\begin{abstract}
:
Understanding and predicting the distribution of organisms in heterogeneous environments lies at the heart of ecology. The spatial distribution of fish populations observed in the wild results from the complex interactions of multiple controls both external or internal to the fish populations. Whilst species distribution models (SDMs) have been mostly concerned with static description of species distribution as a function of environmental constraints, models of animal movements (MAMs) have focussed on the dynamic nature of spatial distribution of groups of individuals under a number of constraints external and internal to the population. Besides SDMs and MAMs, modelling the spatial distribution of fish populations can be achieved by models that are fundamentally static (like SDMs) but can also incorporate many hypotheses on the control of fish spatial distribution (like MAMs). The hypotheses underlying these models need to make sense at the population level - rather than at the individual or species level -we term these 'population distribution models' (PDMs). PDMs are statistical models that rely on several hypotheses, which include: (i) control through geographical attachment, (ii) environmental conditions, (iii) density-dependent habitat selection, (iv) spatial dependency, (v) population demographic structure, (vi) species interactions and (vii) population memory. We review the basis behind each of these conceptual models and we examine corresponding numerical applications. We argue that the conceptual models are complementary rather than competing, that existing numerical applications are still rarely compared and combined, and that PDMs can offer a statistical framework to achieve this. We recommend that the numerical models associated with different hypotheses be constructed within such a common general framework. This will permit evaluation, comparison and combination of the multiple hypotheses on fish spatial distribution. It will ultimately lead to a more comprehensive understanding of the factors controlling the spatial distribution of fish populations and to more accurate predictions in which model uncertainty is accounted for.
\end{abstract}

Keywords: demographic structure; density-dependent habitat selection; environmental control; fish spatial distribution models; multi-model inference; population memory; spatial dependency 
Animal and plant populations are not distributed randomly in space but exhibit spatial patterns, and fish populations are no exception. Understanding what drives these patterns of spatial distribution is both a fundamental ecological question and a requirement for sound management when fish species are of commercial or conservation interest. The various controls on fish spatial distributions can be both external and internal to the populations. External controls, such as environmental forcing, are mainly known to affect the suitability of fish habitats. On the other hand, internal controls such as population size, age structure, fish condition, diversity and behaviour, can also modulate the spatial distribution of fish population, through mechanisms such as density dependence, age- or stage-dependent habitat preference, differential migration capacities, and so on.

In recent decades, a large body of literature has focused on species distribution models (SDMs, see Rushton et al., 2004 for a review). SDMs are mostly concerned with the control of species spatial distribution by the environment. Such approach finds deep theoretical roots in the niche theory as defined by Hutchinson (1957). The theory, which is defined at the species level, is attractive as it can be easily translated into a wide range of statistical models that associate environmental conditions with species presence or abundance. Environment based models are often referred to as habitat models (Guisan and Zimmermann, 2000), species distribution models (Guisan and Thuiller, 2005) or habitat suitability models (Hirzel et al., 2006) and their aim is to relate observations of animal presence or abundance to various attributes of the environment using a statistical method (Randin et al., 2006, Austin, 2002, Rushton et al., 2004, Araújo and Guisan, 2006, Guisan et al., 2006, Austin, 2007, MacNally, 2000, Boisclair, 2001). In essence, SDMs are restricted to modelling species response to the environment but environmental forcing alone cannot be expected to fully explain the spatial distribution of fish populations, unless such forcing is so strong that it over-rides all other drivers. Other mechanisms such as site fidelity, learning behaviour, life-history changes, competition (intra- and inter specific), predator avoidance, spawning behaviour, and exploitation are expected to affect the spatial distribution of fish populations, possibly to a large extent. Ignoring these mechanisms can lead to incomplete or erroneous representations of the processes controlling fish distribution. These processes are complex, interacting, and evolving as populations constantly adapt to new ecological conditions. For this reasons SDMs are often (but not always) used to model the 'potential' spatial distribution of species, that is the distribution resulting from environmental constraints only, which is the geographical realisation of the fundamental niche. Because they are based on niche theory, these models are primarily applicable to species rather than populations. They constitute very useful and powerful tools to model and predict the spatial distribution of species' potential habitats, but are not primarily designed to model and predict actual spatial distribution of animals at the population level. 
Models of animal movements (MAMs) constitute a radically different approach to the description and prediction of animals' spatial distribution. These are primarily concerned with the movement and behaviour of individuals or groups of individuals. They are dynamic rather than static models. When used in marine systems, they are often coupled with hydrodynamic circulation models. MAMs set their foundations on assumptions or empirical knowledge of individuals: physiological tolerance, energy requirements, behaviour, known preys and predators, swimming capacities, interactions with congeners, and so on (Fisken et al., 2007, Gallego et al., 2007, Heath and Gallego, 1998, Huse et al., 2002, Peck and Daewel, 2007). Although MAMs are often built using individual-based models (IBMs), which explicitly represent the movements of individuals or small groups thereof, they are not restricted to IBMs. In some cases, the IBM modelling may be conveniently approximated by advection-diffusion models in which it is not individuals but the density field of the population that is modelled (Faugeras and Maury, 2007). There is a wide range of motivations for constructing models of animal movements in fish, from the understanding of passive larval transport processes to the role of collective behaviour in migration. Like SDMs, MAMs have sometimes been used to represent and predict the spatial distribution of fish populations (see e.g. Lehodey et al., 1998, Lehodey et al., 2008).

Whilst SDMs are well suited to model and predict potential fish species, the use of statistical model for understanding and modelling the controls of fish spatial distribution at the population level has received less attention. The population level (i.e. a group of individuals from the same species which can freely interbreed) can encompass relatively large spatial scales and number of individuals, which distribution is framed by geographical, environmental and historical contingencies. Besides SDMs and MAMs, modelling the spatial distribution of fish populations can be achieved by models which are fundamentally static (like SDMs) but can incorporate many hypotheses on the control of fish spatial distribution (like MAMs). The hypotheses underlying these models need to make sense at the population level - rather than at the individual or species level - and we term these 'population distribution models' (PDMs). Like SDMs, PDMs are constructed using statistical models, but in addition to SDMs, they can incorporate explicit modelling of non-environmental control processes such as site fidelity, spatial dependency, density dependence, species interactions or population memory. Such models may be advantageous when the information necessary to adequately model the movement of fish is poorly known (which is often the case, e.g. vertical and horizontal swimming behaviour), but when information on current and past spatial distribution of the population of interest, spatial distribution of other species and environmental conditions are known.

The intention here, is to revisit the ecological rational behind the conceptual models of spatial distribution of fish populations and to examine and discuss the corresponding numerical applications that have been developed for fish populations. Whilst a review of MAMs would merit special attention these have been deliberately excluded from this study. Instead, the present work focuses on PDMs with which the authors are more familiar. The following conceptual models for explaining fish spatial 
distribution are explored: (i) control through geographical attachment, (ii) environmental conditions, (iii) density-dependent habitat selection, (iv) spatial dependency, (v) population demographic structure, (vi) species interactions (direct and indirect) and (vii) population memory. Numerical applications exist, to variable degrees of development, for each of these hypotheses. We present some of the most common numerical applications, with a focus on models that are amenable to statistical inference and prediction. When developing such spatial distribution models, the issue of scale needs to be carefully considered (e.g. Levin, 1992). Here, we focus on the population level and assume that the spatial scale of investigation encompasses the extent of population distribution and that the resolution is sufficient to discriminate between areas where important differences in mean abundance or environmental conditions do occur. We argue that a common modelling framework, in which numerical models associated with each hypothesis can be constructed, will provide the basis to evaluate, compare and combine models in an objective manner. Under such conditions, it will be possible to test and challenge the ecological hypotheses and to progress in the understanding of what controls the spatial distribution of fish populations. This will also provide tools directly applicable for predicting fish population distribution under a wide range of ecological scenarios.

\section{The multiple controls of population spatial distribution}

Factors that control the spatial distribution of fish populations can be grouped into two main categories, external and internal. External controls, which are often referred to as environmental controls, are independent of population state. Such controls would typically include factor such as hydrological conditions, bottom types, turbidity or oxygen concentration. Interactions with other species (predators, preys and competitors) are also often treated as external controls although they are not strictly so. Internal control are directly linked to the status of the population under study. These typically include density-dependent processes, the effect of demographic structure and historical contingencies (i.e. the past states of the population). Below, we review seven hypotheses of control that are commonly considered for explaining fish population spatial distribution and which include both internal and external controls.

\section{Absence of control}

The absence of control, neither internal nor external is the simplest hypothesis concerning the spatial distribution of fish populations. In such case, the distribution is expected to be unstructured (i.e. to resemble $2 \mathrm{D}$ or $3 \mathrm{D}$ white noise). This situation is never observed in the real world, but we explicitly state this hypothesis here because it is implicitly used in standard statistical tests. When population distribution models are tested using conventional statistical inference, it is often this unrealistic situation that is taken as the null hypothesis against which other hypotheses may be tested. 


\section{Geographical attachment}

In the hypothesis of a geographical control of fish distribution, it is assumed that the presence or abundance of fish is solely determined by the geographical location, i.e. site attachment. There are no explicit processes hypothesized. Contrary to the absence of control, the site attachment hypothesis can often constitute a valid null hypothesis against which other hypotheses can be tested. Physical or biological process which can lead to persistence or variations in population geographical distribution are discussed in the following sections

\section{Environmental conditions}

The environment is usually thought as the major factor that controls the spatial distribution of fish populations. This constitutes an extension - in the geographical space - of the concept of ecological niche (Hutchinson, 1957). The fundamental niche is defined as a hypervolume of $n$ environmental dimensions, each of them representing a environmental factor which may constrain species survival, growth and reproduction. Identification of the environmental factors that should be retained is one of the many challenges for ecologists when studying the environment influence on the spatial distribution of fish populations. These may be classified according to their nature, as resources, direct and indirect gradients and also according to their function, as proximal and distal gradients (Austin, 2002, Austin, 2007). Once the environmental factors have been identified, the form of the relationship that links the environment to the species needs to be specified. In Hutchinson's niche theory, the species response (either biological, physiological and biochemical) along the environmental gradient has a bell-shaped form. This leads to the assumption of the continuum theory from which the response shape of the species is assumed to have a unimodal and symmetric form. However, the response to environmental factors does not always match this theoretical pattern, and interactions between factors may seriously complicate investigations on their respective roles. This can lead to species response taking more complicated shape, e.g. skewed or non-unimodal form (Oksanen and Minchin, 2002). The notion of the habitat is directly derived from the ecological niche concept. In the concept of habitat, the ecological niche is represented by a map on which species-environment relationship has been applied to the environmental spatial pattern observed. Thus, the habitat can be considered as the geographical realisation of the niche.

\section{Density-Dependent Habitat Selection}

In their influential work, Fretwell and Lucas (1970) expressed that the suitability of a particular part of the environment will decrease with an increase in the density of individuals occurring locally. This has formed the basis for density-dependent habitat selection (DDHS) and the original development of ideal free distribution (IFD) theory. In the ideal free distribution, individuals are "ideal" i.e. they possess a complete knowledge of the suitability of the environment and they seek access to habitat with the highest suitability. They are also "free" to access every habitat without any particular cost in time, 
energy or mortality risk. In the ideal free distribution world, individuals distribute themselves in habitats of varying quality in such way that the resulting suitability (often expressed as individual fitness) of every occupied habitat is even. One consequence of DDHS is that populations will tend to occupy wider geographical areas as their size increases while retract to refuge areas when their size decreases, leading to a population abundance-area relationship. However, observed abundance-area relationships may not always result from true DDHS and these should be analysed with caution (see Shepherd and Litvak, 2004 for a discussion on this aspect). DDHS models have found applications in fish ecology mainly through the development of the "basin model" (MacCall, 1990) and its application to the Pacific "northern anchovy" (Engraulis mordax).

The original form of the IFD has been gradually relaxed from the ideal and free assumptions by constraining patch accessibility (Ideal despotic distribution IDD, Fretwell, 1972), including predatorprey dynamics (Sutherland, 1983), allowing for differences in competitive ability between individuals (Sutherland and Parker, 1985, Parker and Sutherland, 1986), including long-term memory of habitat patches (Milinksi, 1994) or accounting for energetic costs of reaching patches (Tyler and Gilliam, 1995).

Self-organising behaviour (area restricted search) by species can also generate large scale patterns through a phenomenon called density-dependent migratory waves. This phenomenon was suggested by Fauchald et al. (2006) as an explanation for the increased aggregation and displacement of Barents sea capelin observed during feeding, in years of high capelin abundance.

\section{Spatial dependency}

Fish spatial distribution in the ocean is directly affected by individual interactions (e.g. schooling or shoaling) and interspecific interactions (e.g. prey searching and predator avoidance behaviours). These interactions result in non-random spatial distributions where groups of individuals tend to aggregate in specific areas whilst being nearly absent from others. Dense fish schools, as observed for many small pelagic fish, are extreme example of aggregated spatial distribution occurring at relatively small scale (few meters to few hundred meters). Shoaling fish will often generate less dense aggregations but will still result in aggregated spatial distributions at relatively small spatial scales. The spatial dependency (i.e. existence of areas of higher and lower densities of fish) can therefore be explained, at least partially, by interactions occurring within the population or between preys and predators. However, when environmental control is spatially structured, fish distribution will also be spatially structured, even if there is no true aggregative process at play. In such situation it is difficult to assign the origin of the spatial dependency observed to endogenous processes (population biological interactions) or to exogenous processes (spatially structured environmental controls). Endogenous spatial contagion may be important to consider and it may vary greatly with time. For example in temperate fish populations 
with contracted spawning season, the spatial distribution may be highly aggregative during spawning and much less during other life-stages.

\section{Demographic structure}

Fish populations are demographically structured, i.e. they are composed of individual of different development stages (larvae, juveniles, adults), different sexes, different ages and different sizes. Habitat occupation by individuals may vary according to these traits. The concept of size-dependent habitat selection was formalised by Werner and Gilliam (1984). This was not done in a spatial context, but rather in a theoretical context in which several habitats with distinct properties are available to a sizestructured population. Particular habitats correspond to optimal sizes of individuals, so it is advantageous for individual fishes to move from one habitat to another, as they grow larger. The principles of the size-dependent habitat selection model outlined by Werner and Gilliam (1984) is that fitness (which they measured as the ratio between natural mortality and growth) is size-dependent and that individuals will inhabit the most suitable habitats according to their size. Experimental work on coral-dwelling goby show that size-dependent spatial organisation resulting from inter-cohort competition can be modified by removing old/large individuals (Hobbs and Munday, 2004). Similarly, habitat modification experiments coupled with variations in large fish densities have shown that juvenile flatfishes may change habitat preference and therefore spatial distribution as a result of increased large fish densities (Ryer et al., 2007). Aside from theoretical and experimental work, empirical evidence for size-dependent spatial organisation is common for marine fish. Small individuals are often found close to the coast in shallow waters whilst larger individuals are found further offshore in deeper waters (see e.g. Chen et al., 1997, Gordoa and Duarte, 1991). Long-range migrating populations such as the Norwegian spring spawning herring display differential distribution with larger/older individuals expanding their distribution much further offshore than do smaller/younger ones (Holst et al., 2004).

There is evidence of age-specific spatial distribution in fish (see e.g. Swain, 1993), but strict agedependent habitat selection seems rare and there is, to our knowledge, little empirical support for it. Instead, age-dependent spatial distribution mostly results from size-dependent habitat selection (above), because older fish tend to be larger than younger ones. Age may also play an important role in the ability of fish individuals and fish populations to memorise and reproduce particular spatial distribution patterns. This is further discussed in the section on memory.

Sex-dependent spatial distribution may be expected when a species displays sex-specific life history tactics. There is evidence of sex-dependent spatial distribution patterns for a number of fish species. For example, in the St Lawrence Swain and Morin (1996) observed that depth distribution of American Plaice (Hippoglossoides platessoides) tended to be more spread out for females than for males. Sex- 
dependent spatial distribution may also be connected with size/age-dependency for hermaphrodite species in which individuals change sex at a given size or age in their life.

In summary, the demographic structure of a given fish population will influence its spatial distribution, primarily through size distribution. Observed differences in distribution at age are most likely to result from size effects rather than from strict age effects. Sex specific spatial distributions are observed for a number of populations, and can be expected when sex-specific life-history tactics are at play or when sex determination is environmentally influenced (Han and Tzeng, 2007).

\section{Species interactions}

The spatial extent and location of fish population is modulated by local resource availability (preys), direct competition for space or food resources (competitors) or mortality (predators, parasites, pathogens). Predators play an important role in shaping the spatial distribution of prey on local and/or regional scales either directly by inflicting mortality on prey or indirectly through risk effects (i.e. by inducing costly antipredator behaviour, Heithaus et al., 2008). Predators displaying adaptive collective self-organising behaviour such as schooling, local enhancement or area-restricted prey search, may create unstable spatial predator-prey interactions on small scales (Abrams, 2007). In some situations, schooling predators may deplete local prey aggregations (Temming et al., 2007). Indirect predatory effects may be equally important in shaping the spatial distribution of prey as direct effects (Creel and Christianson, 2008). Two recent studies have shown that the presence of predators (killer whales and dusky sharks) can change the habitat use of their preys (harbour seal and stellar sea lions) through risk effects (Frid et al., 2008, Frid et al., 2009). In a simple predator-prey context, predators are expected to distribute themselves in areas of high prey densities whereas prey would move away from areas with high predator densities, i.e. a typical 2-way spatial game (e.g., Fauchald, 2009, Sih, 2005). The sign and strength of the spatial correlation between predator and prey abundance depends on whether the predator or the prey distributions are constrained. Constraints imposed on the predator, due for example to inaccessibility to prey refugia, is expected to result in negative predator-prey relationships at specific scale (Fauchald, 2009, Rose and Leggett, 1989). Thus, not surprisingly, studies of spatial predator-prey correlations varies considerably among functional groups such as seabirds (Hunt et al., 1999), fish (e.g. Lehodey et al., 1998) and sea mammals (e.g. Skern-Mauritzen et al., 2009), partly because the predator and prey constraints are likely to vary between functional groups and prey (Sih et al., 1998). The outcome of spatial games, which can include multiple predators as is often observed in the ocean, is difficult to predict.

How interactions between competing species can shape the spatial distributions of populations has been a central issue in terrestrial ecology (see e.g. Pacala and Levin, 1997, Tilman and Kareiva, 1997), but has received far less attention from fish ecologists. In upwelling systems where the spatial distributions of small pelagic fish species can overlap, it has been hypothesised that opposite expansion/contraction 
patterns of sardine and anchovy stocks are related to inter-specific competition (Ward et al., 2001). In theory, two competing species sharing the same resources can coexist if their niche overlap is low or their fitness are equal (Chesson and Kuang, 2008).

\section{Memory}

The spatial distribution of fish populations tends to have a degree of persistence over years and recurrent spawning, nursery or feeding grounds are common for many fish stocks. Memory at the population level memory can result from imprinting of individual in early life stages, which leads to natal homing, a process by which adult fish will tend to migrate back to their place and/or environment of 'birth'. The maintenance of spatial population patterns across years and across generations can also be achieved by the combination of individual memory and social interactions between individuals of the same population or contingent. Individual fish are able to memorise and learn from other fish individuals (Helfman and Schultz, 1984, Brown and Laland, 2003). These two fundamental properties allow newcomers to be entrained into traditional migrations and habitats by older fish (McQuinn, 1997, Corten, 2002). This lead Petitgas et al. (2006) to develop the entrainment hypothesis, a mechanism by which fish population can maintain persistent migratory and spatial distribution patterns over generations while allowing for innovation in particular circumstances. The screening of 11 fish populations (including herring, sardine, whiting, anchovy, bluefin tuna, white perch and striped bass), undertaken during the ICES $^{1}$ workshop WKTEST $^{2}$ (ICES, 2007) revealed that in all cases there was some support for the entrainment hypothesis. Entrainment was demonstrated for Canadian herring (McQuinn, 1997) by showing crossover of individuals between spring- and autumn-spawning contingents. Conditions for entrainment to happen are met when generations overlap in space, length and condition. Because entrainment results in conservatism in habitat use, the occupancy of particular habitats may continue over the life time of several fish generations, even though the suitability of these habitats has become sub-optimal (e.g. variation in feeding grounds of North Sea herring: Corten, 2002). Numerical dominance of naïve fish relative to experienced fish may lead to the colonisation of novel habitats (e.g., variation in wintering habitats of Norwegian spring spawning herring as a result of incoming strong year classes Dragesund et al., 1997, Huse et al., 2002). In contrast, stock collapse is often associated with spatial memory collapse and contingent diversity collapse (e.g. McQuinn, 1997, Corten, 2002, ICES, 2007).

The above studies suggest that spatial distributions of fish populations in the past may partially control their spatial distributions in the future, as long as the conditions that allow for population memory to exist are met (individual memory and trans-generational information sharing).

\footnotetext{
${ }^{1}$ ICES: International Council for the Exploration of the Sea

${ }^{2}$ WKTEST: Workshop on testing the entrainment hypothesis
} 


\section{Multiple controls}

We have presented seven hypotheses which are usual candidates for explaining the observed patterns of fish population spatial distribution (Fig. 1). As much as possible we have tried to isolate each individual hypothesis from the others, for the sake of clarity, and mainly because it is only when the hypotheses are clearly and strictly defined that they can be discussed and challenged in an objective manner. Fish spatial distribution in the wild is complex and the hypotheses presented above are not exclusive of each other. On the contrary, it is expected that fish distribution patterns observed in the wild result from the interplay between several of the hypothesised processes: geographical attachment, environmental conditions, density-dependent habitat selection, spatial dependency, demographic structure, species interactions or memory. As an example, experimental studies on juvenile flatfish have shown that habitat selection can depend upon the combined effects of ontogeny (development), temperature, sediment type and the density of individuals (Laurel et al., 2007), thereby combining three hypotheses (demographic structure, environment and density dependence). Strict abiotic environmental control of species distribution is likely to depend upon the species abundance (at high abundance competition is more likely to have an effect, while at low abundance abiotic factors may dominate). Thus, abiotic control may be more applicable under some conditions (low abundance) than others (Mitchell, 2005).

In this context of multiple controls, testing individual hypotheses and developing single-hypothesis models to represent or predict fish spatial distribution will likely yield poor understanding of the processes at play, even when model predictions apparently fit well with observations. As an example, it is easy to foresee that pure environmental models may fail when a population size dramatically increases or decreases. Similarly, models that ignore species interactions will perform poorly if the abundance of a key predator or prey fluctuates greatly. The question is not to determine whether individual hypotheses are valid but rather to evaluate the relative contribution of the various processes and evaluate the reliability and usefulness of the hypotheses when predicting populations' spatial distribution under observed or projected states of the environment and populations. One way to do so is to translate the hypotheses into numerical models which can be calibrated or fitted to field observations and which can also be evaluated against independent observations. Below, we describe some of the numerical applications currently used for modelling fish population distributions. We then discuss how these models can be evaluated, compared and combined to improve our understanding and predicting capabilities.

\section{Population distribution models}

Many statistical models can ultimately be used to predict fish population spatial distribution, under observed, forecasted or hypothesized conditions. We have chosen to group model types according to the underlying control hypotheses listed above. This is helpful in understanding how each hypothesis is being addressed through numerical models and to highlight the respective strength and weaknesses in 
model developments. We have primarily focussed on PDMs that can be used to predict population distribution (in the sense of statistical predictions), rather than models restricted to strict inference, (i.e. models designed to investigate the relevance of the different hypotheses but that can not be used for statistical predictions, e.g. Mantel test, Dale and Fortin, 2002).

\section{Geographical models}

Geographical models can be constructed from past empirical evidence. For example, regular stock assessment surveys carried out over a number of years can be used to construct empirical average spatial distributions for particular species. This is commonly done for constructing traditional atlases (e.g. online maps of fish species spatial distribution in the North Sea provided by the ICES-Fishmap project, http://www.ices.dk/marineworld/fishmap/ices/). Geographical models are not totally hypothesis-free because they require that the spatial and temporal scales at which the data aggregation is made be defined and that a particular statistical distribution be selected (e.g. Normal, Poisson, etc.). However, because the geographical hypothesis is not process-related, geographical models remain fairly simple to construct and in many cases can serve as the benchmark against which more complex models can be evaluated. Geographical models can be formulated by continuous functions in which presence or abundance is a direct function of continuous geographical coordinates (longitude and latitude). This can be achieved using a suite of possible techniques, including ordinary least square (OLS) regression, generalised additive models (GAMs), regression trees or other. Alternatively, the geographical space may be divided into discrete spatial elements, either regular or not. Regular grids are commonly found in fisheries statistics (e.g. ICES statistical rectangles are $0.5^{\circ}$ latitude and $1.0^{\circ}$ longitude). Regions of variable sizes can also be defined, on the basis of known environmental characteristics. As a result of these constructions, either the rectangle or region identity may be used as predictors of abundance in a given location.

\section{Environment-based models}

Environment-based models aim to relate observations of animal presence or abundance to various attributes of the environment using a statistical method. These are, in essence, SDMs. Many statistical methods can be applied to relate animal presence or abundance to environmental factors. Choice among these methods depends on the nature of biological observations (or biological response). The biological response that is modelled can be presence-only data, presence/absence, count data or continuous data such as density or biomass. For presence only data, methods pertaining to the family of climatic envelopes are generally used (Pearson and Dawson, 2003, Hirzel et al., 2002, Elith et al., 2006, Pearce and Boyce, 2006, Hirzel et al., 2006). Pearce and Boyce (2006) and Elith et al. (2006) provide a synthesis and critique of the methods currently available. For binary, counts and continuous data, classifications and regressions methods have been widely used and most methods are now easily available, either as individual software or often as a library developed in R (Crooks and Soulé, 1999, R 
Development Core Team, 2004, http://www.r-project.org/). Ordinary Least Square regression (OLS), Generalised Linear Models (GLM, McCullagh and Nelder, 1989) and Generalised Additive Models (GAMs, Hastie and Tibshirani, 1990, Guisan et al., 2002, Wood, 2006) have been used to construct environmental models with various statistical distributions and degree of complexity in the response shape. Several methods based on GAMs have been implemented to allow for the automatic selection of environmental predictors (e.g. the $\mathrm{R}$ packages or functions mgcv, GRASP and BRUTO) and the automatic inclusion of interactions between predictors (the Hyperniche software, McCune, 2006). Alternative approaches include Multivariate Adaptive Regression Splines (MARS, Friedman, 1991), Artificial Neural Networks (ANN, Maravelias et al., 2003, Joy and Death, 2004, Wieland and JarreTeichmann, 1997), regression trees (De'ath and Fabricius, 2000, De'ath, 2002, Sutton et al., 2005, Stratoudakis et al., 1998, Usio, 2007) and their boosted form (Friedman et al., 2000, Friedman and Meulma, 2003, Leathwick et al., 2006, Friedman, 2001).

Whilst all the methods described above are designed to model the average biological response to the environment, alternative techniques have been developed to model specific parts (or quantiles) of the response distribution (Mosteller and Tuckey, 1977). Quantile regressions (Koenker and Basset Jr., 1978, Koenker, 2005) are particularly well suited for modelling environment-population relationships in the case of limiting environmental conditions (in the sense of the law of limiting factors, van der Ploeg et al., 1999). Quantile regressions have been applied for various ecological problems (Cade et al., 1999, Cade and Noon, 2003, Planque and Buffaz, 2008, Hiddink, 2005). When applied to the upper distribution quantiles, the method is well suited to model potential habitat in which environment variables can be used to predict potentially suitable areas but are not used to predict the average population response (Vaz et al., 2008, Eastwood et al., 2001, Eastwood et al., 2003). Geographical Weighted Regressions (GWR, Fotheringham et al., 2002) address the problem of space-dependent relationships. They are based on the idea that the link between the species and the environment can vary locally, reflected by the parameters that can vary among the space using a kernel smoothing function.

A very rich and recent literature, which reviews, critically assesses and compares all these techniques is available (Maggini et al., 2006, Moisen and Frescino, 2002, Thuiller, 2003, Segurado and Araújo, 2004, Moisen et al., 2006, Elith and Graham, 2009, Dormann, 2007b, Heikkinen et al., 2006, Vaughan and Ormerod, 2005).

\section{Density-dependent habitat selection and Ideal Free Distribution models}

Numerical models related to density-dependent habitat selection (DDHS) were primarily developed by Fretwell and Lucas (1970) and Fretwell (1972) and are based on the concept of Ideal Free Distribution (IFD). The IFD model is expressed by a suitability index, which depends on the basic local suitability of the habitat and a function of the local population density. At equilibrium, the population is distributed in such a way that the suitability is equal in all occupied habitats (and equal or lower in 
unoccupied ones). Basic suitability is often not directly accessible but it can be derived from empirical relationships such as those obtained in environment-based models. In the specific situation of animal spatial distribution being controlled by the availability of preys and density-dependence, the equation can be written as in Sutherland (1983), where local density depends on the proportion of individuals in a given habitat and the proportion of available resource in this habitat. The equation can be applied for any type of resource (Tyler and Hargrove, 1997). DDHS models that are developed to predict habitat suitability can be written to predict species presence or abundance at given spatial locations. Particular adaptations of the original IFD model have been developed to account for predator-preys dynamics, long-term memory, individual difference in competitive ability, energetic cost of travelling between habitats or anti-predator tactics. Accounts of these developments can be found in Tregenza (1995) and Schilling (2005).

\section{Spatial dependency in models}

Spatial dependency in fish distribution occurs when locations close to each other exhibit more similar values than those further apart. This results in spatial autocorrelation, a statistical issue that has long been recognized (Student, 1914) but which has been integrated in ecological studies only more recently (Legendre, 1993). There has been an extensive development of the tools available to measure, test and account for autocorrelation in species distribution models during the recent decade. It is not the intention here to review the list of possible models available to deal with autocorrelation in habitat models. Such review can be found in Keitt et al. (2002), Segurado et al. (2006), Wintle and Bardos (2006) and Dormann et al. (2007). The following section is restricted to the presentation of models that appear to be particularly suited to deal with the modelling of fish population spatial distribution.

Habitat models that include spatial autocorrelation are usually extensions of models from two opposite origins. They can originate from geostatistical models to which an environmental component is added or from environment-based models to which a spatial component is added (Nishida and Chen, 2004). The result is a combination of environmental control and spatial dependence, which can be estimated sequentially or simultaneously. Geostatistical models are specifically developed to model spatially autocorrelated processes and have been applied to the study and modelling of fish spatial distribution (Petitgas, 2001). In geostatistical models, the spatial prediction is analogous to spatial interpolation and is referred to as "kriging". In co-kriging spatial dependence on variables and co-variables are considered simultaneously when modelling spatial distribution. Regression Kriging (RK) is an example of sequential method that combines predictions from a regression model with kriging of the model residuals. RK methods allow for flexible regression models to be used (e.g., GAMs, GLMs), and a wide variety of predictor variables to be included (Miller et al., 2007). Other methods may partially account for spatio-temporal autocorrelation within regression models. These may include modified wild bootstrap to take into account heteroskedastic errors and build confidence interval of model predictions 
(Llope et al., 2009, Stige et al., 2006). Permutation techniques may also be used to test non parametrically for the significance of the investigated effects to enhance robustness in presence of autocorrelation (Stige et al., 2006).

Autologistic regression (Augustin et al., 1996), allows to model simultaneously environmental effects and spatial dependency with multi-regression implemented with GLM or GAM, and is suited to fit normal (auto-gaussian) and Poisson (auto-Poisson) data. However, autologistic regression have a poor capacity for parameter estimation and limited predictive power in comparison with other methods (Dormann, 2007a, Carl and Kühn, 2007).

Autoregressive models (AR) allow for the inclusion of a term accounting for spatial autocorrelation in addition to environmental factors. Conditional autoregressive models (CAR) and simultaneous autoregressive models (SAR) have been derived from conventional AR models to better estimate the regression and autoregression parameters. In these models, endogenous and exogenous autocorrelation can be included using a term accounting for each of them (Kissling and Carl, 2008). However, as they are based on OLS, only Gaussian distribution can be modelled. For binomial and other distributions, Generalised Estimating Equation (GEE) seems to be a promising method (Carl and Kühn, 2007).

\section{Models that include population structure}

To our knowledge, there is little or no application of statistical fish distribution models that include population demographic structure. Bartolino et al. (2008) proposed a way to test for changes of distribution along a depth gradient in relation to the size of fish and similar approaches may be used to investigate such changes along latitudinal or longitudinal gradients. When demographic structure is believed to influence the geographical distribution of a fish population, a valid strategy is to separate the population in entities that are then modelled separately (e.g. different age/size or sex groups). Spatial distribution models can be constructed, for each sub-group of the population, using the modelling approaches outlined in this review. The spatial distribution of the whole fish population can then be reconstructed by assembling distributions of individual sub-group afterwards (Loots et al., in press, Loots et al., submitted)..

The same would obviously apply when modelling specific life stages or ecophases (i.e. mating, feeding, overwintering, etc.) that are controlled by distinct processes. In such instances, the developed PDMs would not encompass the population as a whole, but only a specific part of the population or of its lifecycle. The PDMs developed for plaice (Loots et al., in press) and whiting (Loots et al., submitted) in the North Sea provide an example of such application restricted to the actively spawning fraction of the population. 
During the last decades, there have been several developments of spatially explicit multispecies models of fish populations, e.g. Ecospace (Walters et al., 1999), Gadget (Begley and Howell, 2004) or Atlantis (Smith et al., 2007) amongst others. These models have been developed to mimic marine ecosystem dynamics and species interaction in time and space. They are generally far more complex than the simpler statistical models considered here (because they simulate the population dynamics by modelling biological processes) and space has often been reduced to a small number of areas or boxes. Species interactions have also been explicitly represented in individual-based models (1995). Statistical models designed to incorporate the effects of species interaction on spatial distribution have been developed (see e.g. Pacala and Levin, 1997, Sutherland and Parker, 1985, Parker and Sutherland, 1986, Sutherland, 1983), but there are only few examples in which such models have been used to predict fish spatial distribution with explicit account for the distribution of other species. The effect of fish preys has been included, often as an additional or transformed environmental variable (as in Lehodey et al., 1998). Spatially explicit statistical models, which incorporate inter- and intra specific interactions in the sea, still remain to be done for most marine populations and systems.

Memory

Memory can be modelled as a factor controlling the spatial distribution of fish populations in a variety of ways. We shall here consider only how it can be implemented in regression models. In a regression modelling approach in which the occurrence of fish is fitted as a response to explicative covariates, the concept of memory can be directly translated into covariates. A variable accounting for population memory can be used as a covariate. Such variable can be similar to that constructed and used in the Eulerian displacement modelling approach. Also, the conditions for entrainment to happen (sensu Petitgas et al., 2006) can be formulated as covariates. For instance the occurrence of older fish in previous years can be used as covariates to predict the spatial distribution of recruits in the current year (Rindorf and Lewy, 2006). The effects of past spatial distributions of the population can be included one or several time steps back in time, in a manner similar to what is commonly done for temporal autoregressive models.

\section{Evaluation and selection of fish spatial distribution models}

\section{Evaluating single models}

The conventional approach for testing the statistical significance of a model is to compare a selected metrics (for example, the parameters of a regression between a given environmental variable and local fish abundance) associated to the model with that same metrics under a null hypothesis (e.g. no relationship between the selected environmental variable and abundance). While this approach is valid if model uncertainty is small (i.e. there is only one or few models to choose from) and the null 
hypothesis is clearly defined and makes biological sense, it may not be appropriate if one or both of these assumptions are violated (Johnson and Omland, 2004). This is unfortunately a common situation when modelling spatial distribution of fish populations. The null hypotheses are rarely explicitly stated in the literature and they often implicitly refer to the total absence of spatial structure and control of fish presence or abundance (the above-mentioned hypothesis of 'absence of control'). Models performing better than the "no control" hypothesis are often taken as being ecologically meaningful because they appear to be statistically significant. However, since most models, even when wrong, can do better that the "no control" one, most studies which only test a single hypothesis will turn out to find their model statistically significant. This is true even when the model displays very poor fitting or predictive performances.

An additional difficulty when testing for individual models is related to spatial and temporal autocorrelation in the data. Fish data is very often autocorrelated in space, time or both, resulting in non-independence between observations. In most statistical tests, individual observations are assumed to be independent from one another, and failure to meet this assumption results in biased statistical tests (Legendre, 1993, Dale and Fortin, 2002). This effect is particularly worrying because it often remains unrecognised and lead to high rejection rates of the null hypothesis, a situation which encourages publication of biased results and use of wrongly specified numerical models.

The relevant performance of spatial distribution models relates to their prediction capabilities. Whilst model-fitting performance can be constantly improved by adding complexity to the model formulation, model-predicting performance will decline after a certain degree of complexity has been reached because added complexity is modelling noise (or error terms) rather than signal in the observation data. This is commonly known as the bias/variance trade-off (Hastie et al., 2001). Model evaluation should therefore be performed on a testing data set independent from the training data set. Truly independent data sets may yet be difficult to obtain because of autocorrelation in the data collected. This point is discussed further in the following section.

\section{Selecting among single-hypothesis based models}

Even when a single ecological hypothesis can be selected as the principal object of investigation, this ecological hypothesis may possibly be expressed in many different numerical formulations. In such case null hypothesis statistical testing (NHST) becomes ill-adapted because the question is no longer to test a unique numerical model against a null model (for the null hypothesis), but rather to compare different models of the same family. As an example, models developed along the lines of environmental control of population spatial distribution may be formulated in very different manners (e.g. GLMs, GAMs, regression trees and so on) and may include different environmental variables or combination thereof. NHST done on each individual model can result in several competing models being significantly better than the null hypothesis. However, comparison of the models cannot be 
achieved through NHST and requires instead multimodel inference. This can be accomplished by an information-theoretic approach as prescribed by Burnham and Anderson (2002), Johnson and Omland (2004), Stephens et al. (2007) and Diniz-Filho et al. (2008).

In multimodel inference, several models are compared on the basis of a distance metrics between the model predictions and the observations. One commonly used metric is the Akaike Information Criterion (AIC, Akaike, 1974), a measure of the likelihood between the fitted values of the model and the observed values, penalised by the number of parameters in the model. Model selection based on AIC is done as a compromise between model complexity and model ability to reproduce the observations. It is possible to compared models by calculating their difference of AIC $\left(\Delta_{\mathrm{i}}\right)$ with the best model and the probability $\left(\mathrm{w}_{\mathrm{i}}\right)$ of each model to be the best model (details on calculation of $\Delta \mathrm{i}$ and wi are given in Burnham and Anderson, 2002). The selection procedure can result in several models being reasonably good candidates for 'best model', so the outcome of multimodel inference may not always be the identification of a unique solution but rather an ensemble of likely solutions. In multimodel selection, the null hypothesis is no longer needed and mis-specification of $\mathrm{H}_{0}$ is therefore no longer an issue.

However, model selection relies on several important assumptions that need to be carefully checked. The first assumption is that the set of available observations has to reflect the underlying 'truth' (e.g. the true spatial distribution of animals). In the case of fish populations, this is not always simple because of limitations in the observational methods. The second assumption is that the true best model needs to be present in the set of candidate models. This implies that the set of candidate models has been accurately defined and that all the reasonable hypotheses are reflected in one or several numerical models. These two assumptions can be considered rather rhetorical, as they can never be totally fulfilled (Link and Barker, 2006). Third, individual observations should be independent. Nonindependence due to autocorrelation in the data will tend to generate longer (with more explanatory variables) models, so that the problem is analogous to the inflated Type I errors in the NHST approach, which tend to give more statistical importance to some explanatory variables than they really have (Diniz-Filho et al., 2008). Quality of observation data, construction of the set of candidate models and data autocorrelation should be carefully checked before model inference is performed.

Following Hastie et al. (2001) we have argued that model evaluation should be performed on data sets independent from those that have been used for model calibration (i.e. parameter estimation). By doing so, model prediction error rather than model fitting error is used as a measure of model performance. This should allow for a better evaluation of model performance when used in a predictive mode. Crossvalidation methods are doing this by splitting the observation data set into a "training" and a "test" data set and evaluating model performance on the latter. The operation is usually repeated several times, so that each observation is used alternatively for training and testing. A fundamental assumption of crossvalidation is that the training and testing data sets are independent. This is often violated because field 
surveys observations are spatially and temporally autocorrelated. This results in apparent predictive performance being closely related to model fitting performances, and will usually lead to selection of complex models with low bias and high variance, i.e. with low predictive power (Loots et al., in press, Telford and Birks, 2005). Unless the absence of autocorrelation has been demonstrated, models should be evaluated on independent datasets rather than using standard cross-validation methods. One way to partially overcome this difficulty may be to exclude one or several years of observation from the training dataset and use them only for testing (as in Loots et al., in press). This testing dataset may be considered as an independent realisation of the underlying processes. The operation may be repeated as many times as there are years in the dataset. Such approach is valid when temporal autocorrelation is expected to be negligible so that datasets from different years can be considered independent. It may be problematic if mechanisms generating year-to-year memory - of the population spatial distribution - are at play.

In this section, we have concentrated on multi-model inference based on AIC criteria, as advocated in Burnham and Anderson (2002) but alternative promising approaches such as Bayesian based methods and hierarchical modelling are available (Soetaert and Herman, 2009, Cressie et al., 2009, Thuiller et al., 2008) albeit only seldom used in marine ecology yet.

\section{Towards a modelling framework for combining multiple hypotheses}

The causes behind the true spatial distribution of fish populations are numerous and our perception of such distribution is only accessible through limited observations. The processes controlling fish spatial distribution at the population level are many, complex and are likely to vary with specific populations and geographical regions. What really controls fish population spatial distribution is most likely a combination of all the processes identified in the sections above. Any attempt to describe and model fish spatial distribution with only one of these hypotheses is likely to generate poor results or even fail. More promising strategies include the construction of models that include several hypotheses. This can be achieved by combining the individual models presented above into more complex models that can be tested through multimodel evaluation and selection procedures. We recommend that models of different levels of complexity be build from the existing knowledge and hypotheses that are specific to the population studied. Constructing such candidate models is not simple, but following recommendations that apply for model selection is useful. These include 1) the selection of meaningful variables (which can be associated with causal factors), 2) the (theoretical) justification of functions that defines the relationships between controls and responses, and 3) the error structure of the model. Ultimately, the number of candidate models should be small enough to avoid generating so many models that spurious findings become likely (Johnson and Omland, 2004). A strategy consisting in the construction of all possible combination of models is proscribed by Burnham and Anderson (2002), a view supported by recent studies (Dormann et al., 2008, Murtaugh, 2009) showing that stepwise 
selection or best-subset approaches can perform as well as exhaustive subset selection, but contrasting with Whittingham et al. (2006) who recommend considering all possible model combinations. The principles of model selection and the associated theoretical approach are now well developed and technically available to the community of marine and fish ecology researchers (see e.g. Hilborn and Mangel, 1997, Burnham and Anderson, 2002) So, if models can be constructed to match working hypotheses, these will be amenable to model selection and the hypotheses - of combination thereof may be compared and selected. What remains largely unexplored today is the combination of hypotheses through integrated spatial distribution models. Evidence exists that multiple controls of spatial distribution or habitat selection is at play (see e.g. Laurel et al., 2007) but population distribution models which integrate several controlling hypotheses are still the exception. This may result from differences in the mathematical formulation of the various types of models, which makes them difficult to assemble. For example, whilst all models can be applied to predict abundance (or presence) at a given geographical location (i.e. they have the same output variable), they may request input information of different type: geographical models rely on geographical coordinates only, environmental models necessitate additional observed or modelled environmental conditions, DDHS and spatial dependency models require local or neighbouring densities to be known (a difficult situation since this is what the model is trying to predict), and memory models require knowledge about past population states. How these models can be assembled remains a challenge to marine and fisheries ecologists. Selection of models from different 'families' or hybrid models is also challenging, mostly because the amount of independent information used in these models is often poorly estimated as a result of strong spatial and temporal autocorrelation in the data. When this is the case, model selection techniques will tend to favour complex models that have lower bias but also less predictive power. Finally, if and when appropriate models can be developed to predict fish spatial distribution, model selection procedure may lead to the selection of more than one 'best' model. This happens when the data available is not sufficient to resolve model uncertainty. Researchers are then left with a subset of possible models, structurally different from one another but with similar performances. In such situation, multiple models can be used within an appropriate ensemble-forecasting framework. The technique, if used appropriately, can lead to robust predictions without the need to identify a unique best model (Araújo and New, 2007). Some examples of methods used for combining multiple model predictions can be found in Link and Barker (2006), Thomson et al. (2007), Dormann et al. (2008) or Butler et al. (2009).

Whatever the final set of models may be retained in a particular case study, non-stationarity or abrupt environmental shifts are likely to reduce the predictive ability of population distribution models. This is a common problem with most, if not all, statistical predictive models (see e.g. Zurell et al., 2009 on SDMs). The identification of the various sources of uncertainties in ensemble modelling remains a major issue for any attempt to forecast species distribution under anticipated future conditions, and is a 
currently a very active field of research (Diniz-Filho et al., 2009). In may instances, PDMs may prove more useful to explore possible outcomes of climate and/or management scenarios rather than to provide accurate predictions of future distributions.

\section{Conclusions}

Observed patterns of fish population spatial distributions result from multiple controls that are not exclusive of one another. For each hypothesis of control, population distribution models can and have been developed and these models can be evaluated, combined and compared. Whilst SDMs have been used to investigate and model the distribution of fish species under environmental controls only, PDMs can be used to investigate a wider range of control mechanisms, including environmental, biological (intrinsic and extrinsic) and temporal hypotheses. When the models are constructed to predict fish spatial distribution under known or hypothesised conditions, we recommend that they should be evaluated on their predictive rather than data fitting performance. Predicting the distribution of marine fish populations is becoming a pressing issue and global scale predictions are currently being developed (Cheung et al., 2008). These require models and numerical tools that are appropriate to unravel the underlying mechanisms and accurately predict spatial patterns under plausible future scenarios, and the general approach outlined here should prove useful in achieving this goal. Comparing and combining population distribution models that are structurally different remains a major challenge for marine and fisheries ecologists. Multi-model inference may provide an adequate framework to conduct such studies as seen from recent modelling on fish spawning habitat (Loots et al., in press, Loots et al., submitted). Because of the complex and adaptive nature of marine populations and ecosystems, a certain degree of indetermination with regards to the 'best' models will always remain. Such model uncertainty should be accounted for when predicting spatial distributions, possibly through ensemble forecasting.

\section{Acknowledgments}

The authors are grateful to EUR-OCEANS (http://www.eur-oceans.org), a European Network of Excellence co-funded by the European Commission (FP 6, contract n8511106), which supported a summer school during which many of the ideas presented in this paper were discussed (http://www.euroceans.eu/eamr/school/habitat/). This work was part-funded by the EU as part of the RECLAIM project (STREP-FP6). C. Loots acknowledges financial support by the Conseil Régional de Nord Pas-deCalais. S. Vaz received additional financial support by the Franco-British INTERREG IIIA initiative of the European Regional Development Fund (Priority 3, Measure 9), as part of the Channel Habitat Atlas for Marine Resource Management (CHARM) Phase II Project. 


\section{References}

Abrams, P. (2007) Habitat choice in predator-prey systems: spatial instability due to interacting adaptive movements. Am. Nat., 169, 581-594.

Akaike, H. (1974) A new look at the statistical model identification. IEEE Transactions on Automatic Control, 19, 716-723.

Araújo, M.B. and Guisan, A. (2006) Five (or so) challenges for species distribution modelling. $J$. Biogeogr., 33, 1677-1688.

Araújo, M.B. and New, M. (2007) Ensemble forecasting of species distributions. TREE, 22, 42-47.

Augustin, N.H., Mugglestone, M.A. and Buckland, S.T. (1996) An autologistic model for the spatial distribution of wildlife. J. Appl. Ecol., 33, 339-347.

Austin, M. (2002) Spatial prediction of species distribution: an interface between ecological theory and statistical modelling. Ecol. Model., 157, 101-118.

Austin, M. (2007) Species distribution models and ecological theory: a critical assessment and some possible new approaches. Ecol. Model., 200, 1-19.

Bartolino, V., Ottavi, A., Colloca, F., Ardizzone, G.D. and Stefansson, G. (2008) Bathymetric preferences of juvenile European hake (Merluccius merluccius). ICES J. Mar. Sci., 65, 963969.

Begley, J. and Howell, D. (2004) An Overview of Gadget, the Globally applicable Area- 13 Disaggregated General Ecosystem Toolbox. ICES CM, 2004/FF:13.

Boisclair, D. (2001) Fish habitat modeling: from conceptual framework to functional tools. Can. J. Fish. Aquat. Sci., 58, 1-9.

Brown, C. and Laland, K.N. (2003) Social learning in fishes: a review. Fish Fish., 4, 280-288.

Burnham, K.P. and Anderson, D.R. (2002) Model selection and multimodel inference: a practical information-theoretic approach. New York: Springer, xxvi, 488 s.pp.

Butler, A., Doherty, R.M. and Marion, G. (2009) Model averaging to combine simulations of future global vegetation carbon stocks. Environmetrics, 20, 791-811.

Cade, B.S. and Noon, B.R. (2003) A gentle introduction to quantile regression for ecologists. Front. Ecol. Environ., 1, 412-420.

Cade, B.S., Terrell, J.W. and Schroeder, R.L. (1999) Estimating effects of limiting factors with regression quantiles. Ecology, 80, 311-323.

Carl, G. and Kühn, I. (2007) Analyzing spatial autocorrelation in species distributions using Gaussian and logit models. Ecol. Model., 207, 159-170.

Chen, Y., Liggins, G.W., Graham, K.J. and Kennelly, S.J. (1997) Modelling the length-dependent offshore distribution of redfish, Centroberyx affinis. Fish. Res., 29, 39-54.

Chesson, P. and Kuang, J.J. (2008) The interaction between predation and competition. Nature, 13, 235-238.

Cheung, W.W.L., Lam, V.W.Y. and Pauly, D. (2008) Modelling present and climate-shifted distribution of marine fishes and invertebrates. The Fisheries Center, University of British Columbia, 16(3). 72pp.

Corten, A. (2002) The role of "conservatism" in herring migrations. Rev. Fish Biol. Fish., 11, 339-361.

Creel, S. and Christianson, D. (2008) Relationships between direct predation and risk effects. TREE, 23, 194-201. 
Cressie, N., Calder, C.A., Clark, J.S., Ver Hoef, J.M. and Wikle, C.K. (2009) Accounting for uncertainty in ecological analysis: the strength and limitations of hierarchical statistical modeling. Ecol. Appl., 19, 553-570.

Crooks, K. and Soulé, M.E. (1999) Mesopredator release and avifaunal extinctions in a fragmented system. Nature, 400, 563-566.

Dale, M.R.T. and Fortin, M.-J. (2002) Spatial autocorrelation and statistical tests in ecology. Ecoscience, 9, 162-167.

De'ath, G. (2002) Multivariate regression trees: a new technique for modeling species-environment relationships. Ecology, 83, 1105-1117.

De'ath, G. and Fabricius, K.E. (2000) Classification and regression trees: a powerful yet simple technique for ecological data analysis. Ecology, 81, 3178-3192.

Diniz-Filho, J.A.F., Bini, L.M., Rangel, T.F., Loyola, R.D., Hof, C., NoguÈs-Bravo, D. and Ara'jo, M.B. (2009) Partitioning and mapping uncertainties in ensembles of forecasts of species turnover under climate change. Ecography, 32, 897-906.

Diniz-Filho, J.A.F., Rangel, T.F.L.V.B. and Bini, L.M. (2008) Model selection and information theory in geographical ecology. Global Ecol. Biogeogr., 17, 479-488.

Dormann, C.F. (2007a) Assessing the validity of autologistic regression. Ecol. Model., 207, 234-242.

Dormann, C.F. (2007b) Promising the future? Global change projections of species distributions. Basic Appl. Ecol., 8, 387-397.

Dormann, C.F., McPherson, J.M., Araujo, M.B., Bivand, R., Bolliger, J., Carl, G., Davies, R.G., Hirzel, A., Jetz, W., Kissling, W.D., Kühn, I., Ohlemüller, R., Peres-Neto, P.R., Reineking, B., Schröder, B., Schurr, F.M. and Wilson, R. (2007) Methods to account for spatial autocorrelation in the analysis of species distributional data: a review. Ecography, 30, 609-628.

Dormann, C.F., Schweiger, O., Arens, P., Augenstein, I., Aviron, S., Bailey, D., Baudry, J., Billeter, R., Bugter, R., Bukacek, R., Burel, F., Cerny, M., De Cock, R., De Blust, G., DeFilippi, R., Diekotter, T., Dirksen, J., Durka, W., Edwards, P.J., Frenzel, M., Hamersky, R., Hendrickx, F., Herzog, F., Klotz, S., Koolstra, B., Lausch, A., Le Coeur, D., Liira, J., Maelfait, J.P., Opdam, P., Roubalova, M., Schermann-Legionnet, A., Schermann, N., Schmidt, T., Smulders, M.J.M., Speelmans, M., Simova, P., Verboom, J., van Wingerden, W. and Zobel, M. (2008) Prediction uncertainty of environmental change effects on temperate European biodiversity. Ecol. Lett., 11, 235-244.

Dragesund, O., Johannessen, A. and Ulltang, Ø. (1997) Variations in migration and abundance of the Norwegian spring spawning herring (Clupea harengus). Sarsia, 82, 97-105.

Eastwood, P.D., Meaden, G.J., Carpentier, A. and Rogers, S.I. (2003) Estimating limits to the spatial extent and suitability of sole (Solea solea) nursery grounds in the Dover Strait. J. Sea Res., 50, 151-165.

Eastwood, P.D., Meaden, G.J. and Grioche, A. (2001) Modelling spatial variations in spawning habitat suitability for the sole Solea solea using regression quantiles and GIS procedures. Mar. Ecol. Prog. Ser., 224, 251-266.

Elith, J. and Graham, C.H. (2009) Do they? How do they? WHY do they differ? On finding reasons for differing performances of species distribution models. Ecography, 32, 66-77.

Elith, J., H. Graham, C., P. Anderson, R., Dudik, M., Ferrier, S., Guisan, A., J. Hijmans, R., Huettmann, F., R. Leathwick, J., Lehmann, A., Li, J., G. Lohmann, L., A. Loiselle, B., Manion, G., Moritz, C., Nakamura, M., Nakazawa, Y., McC. M. Overton, J., Townsend Peterson, A., J. Phillips, S., Richardson, K., Scachetti-Pereira, R., E. Schapire, R., Soberon, J., Williams, S., S. Wisz, M. and E. Zimmermann, N. (2006) Novel methods improve prediction of species' distributions from occurrence data. Ecography, 29, 129-151. 
Fauchald, P. (2009) Spatial interaction between seabirds and prey: review and synthesis. Mar. Ecol. Prog. Ser., 391, 139-151.

Fauchald, P., Mauritzen, M. and Gjøsæter, H. (2006) Density-dependent migratory waves in the marine pelagic ecosystem. Ecology, 81, 773-783.

Faugeras, B. and Maury, O. (2007) Modeling fish population movements: From an individual-based representation to an advection-diffusion equation. J. theor. Biol., 247, 837-848.

Fiksen, Ø., Giske, J. and Slagstad, D. (1995) A spatially explicit fitness-based model of capelin migrations the Barents Sea. Fish. Oceanogr., 4, 193-208.

Fisken, Ø., Jørgensen, C., Kristiansen, R., Vikebø, F. and Huse, G. (2007) Linking behavioural ecology and oceanography: larval behaviour determined growth, mortality and dispersal. Mar. Ecol. Prog. Ser., 347, 195-205.

Fotheringham, A.S., Brunsdon, C. and Charlton, M. (2002) Geographically Weighted Regression: The analysis of spatially varying relationships. Chichester.: Wiley \& Sons.

Fretwell, S. (1972) Populations in a seasonal environment. New Jersey: Princeton University Press, $217 \mathrm{pp}$.

Fretwell, S. and Lucas, H.L. (1970) On territorial behaviour and other factors influencing habitat distribution in birds. Acta Biotheor., 19, 16-36.

Frid, A., Baker, G.G. and Dill, L.M. (2008) Do shark declines create fear-released systems. Oikos, 117, 191-201.

Frid, A., Burns, J., Baker, G.G. and Thorne, R.E. (2009) Predicting synergistic effects of resources and predators on foraging decisions by juvenile sea lions. Oecologia, 158, 775-786.

Friedman, J.H. (1991) Multivariate adaptive regression splines. Ann. Stat., 19, 1-67.

Friedman, J.H. (2001) Greedy function approximation: the gradient boosting machine. Ann. Stat., 29, 1189-1232.

Friedman, J.H., Hastie, T.J. and Tibshirani, R.J. (2000) Additive logistic regression: a statistical view of boosting. Ann. Stat., 28, 337-407.

Friedman, J.H. and Meulma, J.J. (2003) Multiple additive regression trees with application in epidemiology. Statistics in Medecine, 22, 1365-1381.

Gallego, A., North, E.W., Petitgas, P. and Browman, H.I. (2007) Advances in modelling physicalbiological interactions in fish early life history. Mar. Ecol. Prog. Ser., 347, 121-306.

Gordoa, A. and Duarte, C.M. (1991) Size-dependent spatial distribution of hake (Merluccius capensis and Merluccius paradoxus) in Namibian waters. Can. J. Fish. Aquat. Sci., 48, 2095-2099.

Guisan, A., Edwards, T.C. and Hastie, T.J. (2002) Generalized linear and generalized additive models in studies of species distributions: setting the scene. Ecol. Model., 157, 89-100.

Guisan, A., Lehmann, A., Ferrier, S., Austin, M., Overton, J.M.C., Aspinall, R. and Hastie, T.J. (2006) Making better biogeographical predictions of species' distributions. J. Appl. Ecol., 43, 386-392.

Guisan, A. and Thuiller, W. (2005) Predicting species distribution: offering more than simple habitat models. Ecol. Lett., 8, 993-1009.

Guisan, A. and Zimmermann, N.E. (2000) Predictive habitat distribution models in ecology. Ecol. Model., 135, 147-186.

Han, Y.S. and Tzeng, W.N. (2007) Sex-dependent habitat use by the Japanese eel Anguilla japonica in Taiwan. Mar. Ecol. Prog. Ser., 338, 193-198.

Hastie, T., Tibshirani, R.J. and Friedman, J.H. (2001) The elements of statistical learning. SpringerVerlag. 
Hastie, T.J. and Tibshirani, R.J. (1990) Generalized additive models.: Chapman and Hall, 335pp.

Heath, M.R. and Gallego, A. (1998) Bio-physical modelling of the early life stages of haddock, Melanogrammus aeglefinus, in the North Sea. Fish. Oceanogr., 7, 110-125.

Heikkinen, R.K., Luoto, M., Araujo, M.B., Virkkala, R., Thuiller, W. and Sykes, M.T. (2006) Methods and uncertainties in bioclimatic envelope modelling under climate change. Prog. Phys. Geogr., 30, 751-777.

Heithaus, M.R., Frid, A., Wirsing, A.J. and Worm, B. (2008) Predicting ecological consequences of marine top predator declines. TREE, 23, 202-210.

Helfman, G. and Schultz, E. (1984) Social transmission of behavioural traditions in a coral reef fish. Anim. Behav., 32, 379-384.

Hiddink, J.G. (2005) Implications of Liebig's law of the minimum for the use of ecological indicators based on abundance. Ecography, 28, 264-271.

Hilborn, R. and Mangel, M. (1997) The ecological detective. Princeton: Princeton University Press, $315 \mathrm{pp}$.

Hirzel, A.H., Hausser, J., Chessel, D. and Perrin, N. (2002) Ecological-niche factor analysis: how to compute habitat-suitability maps without absence data? Ecology, 83, 2027-2036.

Hirzel, A.H., Le Lay, G., Helfer, V., Randin, C. and Guisan, A. (2006) Evaluating the ability of habitat suitability models to predict species presences. Ecol. Model., 199, 142-152.

Hobbs, J.P.A. and Munday, P.L. (2004) Intraspecific competition controls spatial distribution and social organisation of the coral-dwelling goby Gobiodon histrio. Mar. Ecol. Prog. Ser., 278, 253-259.

Holst, J.C., Røttingen, I. and Melle, W. (2004) The herring. In: The Norwegian Sea ecosystem. H.R. Skjoldal, R. Sætre, A. Færnö, O.A. Misund and I. Røttingen (eds) Trondheim, Norway: Tapir Academic Press. pp. 203-226.

Hunt, G.L., Mehlum, F., Russel, R.W., Irons, D., Decker, M.B. and Becker, P.H. (1999) Physical processes, prey abundance, and the foraging ecology of sea birds. In: Proc 22nd Int. Ornithol. Congr. Birdlife South Africa. N.J. Adams and R.H. Slotow (eds) Durban. pp. 2040-2046.

Huse, G., Railsback, S. and Fernö, A. (2002) Modelling changes in migration pattern of herring: collective behaviour and numerical domination. J. Fish Biol., 60, 571-582.

Hutchinson, G.E. (1957) Concluding remarks- Cold Spring Harbor Symposia on Quantitative Biology. 22:415-427. Reprinted in 1991: Classics in Theoretical Biology. Bull. Math. Biol., 53, 193-213.

ICES (2007) Report of the workshop on testing the entrainment hypothesis (WKTEST). ICES CM, 2007 / LRC:10, 124pp.

Johnson, J.B. and Omland, K.S. (2004) Model selection in ecology and evolution. TREE, 19, 101-108.

Joy, M.K. and Death, R.G. (2004) Predictive modelling and spatial mapping of freshwater fish and decapod assemblages using GIS and neural networks. Freshwater Biol., 49, 1036-1052.

Keitt, T.H., Bjørnstad, O.N., Dixon, P.M. and Citron-Pousty, S. (2002) Accounting for spatial pattern when modeling organism-environment interactions. Ecography, 25, 616-625.

Kissling, W.D. and Carl, G. (2008) Spatial autocorrelation and the selection of simultaneous autoregressive models. Global Ecol. Biogeogr., 17, 59-71.

Koenker, R. (2005) Quantile regression. New York, U.S.A.: Cambridge University Press, 349pp.

Koenker, R. and Basset Jr., G. (1978) Regression quantiles. Econometrica, 46, 33-50.

Laurel, B.J., Sroner, A.W. and Hurst, T.P. (2007) Density-dependent habitat selection in marine flatfish: the dynamic role of ontogeny and temperature. Mar. Ecol. Prog. Ser., 338, 183-192. 
Leathwick, J.R., Elith, J. and Hastie, T. (2006) Comparative performance of generalized additive models and multivariate adaptive regression splines for statistical modelling of species distributions. Ecol. Model., 199, 188-196.

Legendre, P. (1993) Spatial autocorrelation: trouble or new paradigm? Ecology, 74, 1659-1673.

Lehodey, P., Andre, J.-M., Bertignac, M., Hampton, J., Stoens, A., Menkes, C., Memery, L. and Grima, N. (1998) Predicting skipjack tuna forage distributions in the equatorial Pacific using a coupled dynamical bio-geochemical model. Fish. Oceanogr., 7, 317-325.

Lehodey, P., Senina, I. and Murtugudde, R. (2008) A spatial ecosystem and populations dynamics model (SEAPODYM) - Modeling of tuna and tuna-like populations. Prog. Oceanogr., 78, 304318.

Levin, S.A. (1992) The problem of pattern and scale in ecology. Ecology, 73, 1943-1967.

Link, W.A. and Barker, R.J. (2006) Model weights and the foundations of multimodel inference. Ecology, 87, 2626-2635.

Llope, M., Chan, K.S., Ciannelli, L., Reid, P.C., Stige, L.C. and Stenseth, N.C. (2009) Effects of environmental conditions on the seasonal distribution of phytoplankton biomass in the North Sea. Limol. Oceanogr., 54, 512-524.

Loots, C., Vaz, S., Planque, B. and Koubbi, P. (in press) What controls the spatial distribution of North Sea plaice spawning population? Confronting ecological hypotheses through a model selection framework. ICES J. Mar. Sci.

Loots, C., Vaz, S., Planque, B. and Koubbi, P. (submitted) Identifying processes that control the spawning distribution of North Sea whiting using multi model inference.

MacCall, A.D. (1990) Dynamic geography of marine fish populations. Washington: University of Washington Press, 153pp.

MacNally, R. (2000) Regression and model-building in conservation biology, biogeography and ecology: The distinction between - and reconciliation of - 'predictive' and 'explanatory' models. Biodivers. Conserv., 9, 655-671.

Maggini, R., Lehmann, A., Zimmermann, N.E. and Guisan, A. (2006) Improving generalized regression analysis for the spatial prediction of forest communities. J. Biogeogr., 33, 17291749 .

Maravelias, C., D., Haralabous, J. and Papaconstantinou, C. (2003) Predicting demersal fish species distributions in the Mediterranean Sea using artificial neural networks. Mar. Ecol. Prog. Ser., 255, 249-258.

McCullagh, P. and Nelder, J.A. (1989) Generalized linear models, Monographs on statistics and applied probability 37,2 nd ed.

McCune, B. (2006) Non-parametric habitat models with automatic interactions. J. Veg. Sci., 17, 819830.

McQuinn, I.H. (1997) Metapopulations and the Atlantic herring. Rev. Fish Biol. Fish., 7, 297-329.

Milinksi, M. (1994) Long-term memory for food patches and implications for ideal free distribution in sticklebacks. Ecology, 75, 1150-1156.

Miller, J., Franklin, J. and Aspinall, R. (2007) Incorporating spatial dependence in predictive vegetation models. Ecol. Model., 202, 225-242.

Mitchell, S.C. (2005) How useful is the concept of habitat? - a critique. Oikos, 110, 634-638.

Moisen, G.G., Edwards, J.T.C. and Osborne, P.E. (2006) Further advances in predicting species distributions. Ecol. Model., 199, 129-131. 
Moisen, G.G. and Frescino, T.S. (2002) Comparing five modelling techniques for predicting forest characteristics. Ecol. Model., 157, 209-225.

Mosteller, F. and Tuckey, J.W. (1977) Data analysis and regression. Reading, MA: Addison-Wesley.

Murtaugh, P.A. (2009) Performance of several variable-selection methods applied to real ecological data. Ecol. Lett., 12, 1061-1068.

Nishida, T. and Chen, D.G. (2004) Incorporating spatial autocorrelation into the general linear model with an application to the yellowfin tuna (Thunnus albacares) longline CPUE data. Fish. Res., 70, 265-274.

Oksanen, J. and Minchin, P.R. (2002) Continuum theory revisited: what shape are species responses along ecological gradients? Ecol. Model., 157, 119-129.

Pacala, S.W. and Levin, S.A. (1997) Biologically generated spatial pattern and the coexistence of competing species. In: Spatial Ecology : the role of space in population dynamics and interspecific interactions. D. Tilman and P. Kareiva (eds) Columbia and Princeton: University Presses of California. pp. 204-232.

Parker, G.A. and Sutherland, W.J. (1986) Ideal free distribution when individuals differ in competitive ability: phenotype-limited ideal free models. Anim. Behav., 34, 1222-1242.

Pearce, J.L. and Boyce, M. (2006) Modelling distribution and abundance with presence-only data. $J$. Appl. Ecol., 43, 405-412.

Pearson, R.G. and Dawson, T.P. (2003) Predicting the impacts of climate change on the distribution of species: are bioclimate envelope models useful? Global Ecol. Biogeogr., 12, 361-372.

Peck, M. and Daewel, U. (2007) Physiological based limits to food consumption, and individual-based modeling of foraging and growth of larval fish. Mar. Ecol. Prog. Ser., 347, 171-183.

Petitgas, P. (2001) Geostatistics in fisheries survey design and stock assessment: models, variances and applications. Fish Fish., 2, 231-249.

Petitgas, P., Reid, D., Planque, B., Nogueira, E., O'Hea, B. and Cotano, U. (2006) The entrainment hypothesis: an explanation for the persistence and innovation in spawning migration and life cycle patterns. ICES CM, B:07, 9pp.

Planque, B. and Buffaz, L. (2008) Quantile regression models for fish recruitment-environment relationships - four case studies. Mar. Ecol. Prog. Ser., 357, 213-223.

$\mathrm{R}$ Development Core Team (2004) $R$ : A language and environment for statistical computing. $R$ Foundation for Statistical Computing. Vienna, Austria.: ISBN 3-900051-00-3, URL http://www.R-project.org.

Randin, C.F., Dirnbock, T., Dullinger, S., Zimmermann, N.E., Zappa, M. and Guisan, A. (2006) Are niche-based species distribution models transferable in space? J. Biogeogr., 33, 1689-1703.

Rindorf, A. and Lewy, P. (2006) Warm windy winters drive cod north and homing keeps them there. $J$. Appl. Ecol., 43, 445-453.

Rose, G.A. and Leggett, W.C. (1989) Interactive effects of geophysically-forced sea temperatures and prey abundance on mesoscale coastal distributions of a marine predator, Atlantic cod (Gadus morhua). Can. J. Fish. Aquat. Sci., 46, 1904-1913.

Rushton, S.P., Ormerod, S.J. and Kerby, G. (2004) New paradigms for modelling species distributions? J. Appl. Ecol., 41, 193-200.

Ryer, C.H., Stoner, A.W., Spencer, M.L. and Abookire, A.A. (2007) Presence of larger flatfish modifies habitat preference by Age-0 northern rock sole Lepidopsetta polyxystra. Mar. Ecol. Prog. Ser., 342, 227-238.

Schilling, N.S. (2005) Survival of the fittest: fish in patchy environments show ideal free distribution (IFD). Eukaryon, 1, 11-16. 
Segurado, P. and Araújo, M.B. (2004) An evaluation of methods for modelling species distributions. $J$. Biogeogr., 31, 1555-1568.

Segurado, P., Araújo, M.B. and Kunin, W.E. (2006) Consequences of spatial autocorrelation for nichebased models. J. Appl. Ecol., 43, 433-444.

Shepherd, T.D. and Litvak, M.K. (2004) Density-dependent habitat selection and the ideal free distribution in marine fish spatial dynamics: considerations and cautions. Fish Fish., 5, 141152.

Sih, A. (2005) Predator-prey space use as an emergent outcome of a behavioral response race. In: Ecology of predator-prey interactions. P. Barbosa and I. Castellanos (eds) New York: Oxford University Press. pp. 240-255.

Sih, A., Englund, G. and Wooster, D. (1998) Emergent impacts of multiple predators on prey. TREE, 13, 350-355.

Skern-Mauritzen, M., Skaug, H.J. and Øien, N. (2009) Line transects, environmental data and GIS: cetacean habitat and prey selection along the Barents Sea shelf edge. In: North Atlantic Sighting Surveys, counting whales in the North Atlantic, 1987-2001. N. Øen and D. Pike (eds) Tromsø: North Atlantic Marine Mammal Commission Scientific Publications. pp. 179-200.

Smith, A.D.M., Fulton, E.J., Hobday, A.J., Smith, D.C. and Shoulder, P. (2007) Scientific tools to support the practical implementation of ecosystem-based fisheries management. ICES J. Mar. Sci., 64, 633-639.

Soetaert, K. and Herman, P.M.J. (2009) A Practical Guide to Ecological Modelling. Using $R$ as a Simulation Platform. Springer.

Stephens, P.A., Buskirk, S.W. and del Rio, C.M. (2007) Inference in ecology and evolution. TREE, 22, 192-197.

Stige, L.C., Ottersen, G., Brander, K., Chan, K.S. and Stenseth, N.C. (2006) Cod and climate: effect of the North Atlantic Oscillation on recruitment in the North Atlantic. Mar. Ecol.-Prog. Ser., 325, 227-241.

Stratoudakis, Y., Gallego, A. and Morrison, J.A. (1998) Spatial distribution of developmental egg ages within a herring Clupea harengus spawning ground. Mar. Ecol. Prog. Ser., 174, $27-32$.

Student (1914) The elimination of spurious correlation due to position in time or space. Biometrika, 10, 179-181.

Sutherland, W.J. (1983) Aggregation and the 'ideal free' distribution. J. Anim. Ecol., 52, 821-828.

Sutherland, W.J. and Parker, G.A. (1985) Distribution of unequal competitors. In: Behavioural Ecology. 25th Symposium of the British Ecological Society. R.M. Sibly and R.H. Smith (eds): Blackwell Scientific. pp. 255-275.

Sutton, C.D., Rao, C.R., Wegman, E.J. and Solka, J.L. (2005) Classification and regression trees, bagging, and boosting. In: Handbook of Statistics: Elsevier. pp. 303-329.

Swain, D.P. (1993) Age- and density-dependent bathymetric pattern of Atlantic cod (Gadus morhua) in the southern Gulf of St. Lawrence. Can. J. Fish. Aquat. Sci., 50, 1255-1264.

Swain, D.P. and Morin, R. (1996) Relationships between geographic distribution and abundance of American plaice (Hippoglossoides platessoides) in the southern Gulf of St Lawrence. Can. J. Fish. Aquat. Sci., 53, 106-119.

Telford, R.J. and Birks, H.J.B. (2005) The secret assumption of transfer functions: problems with spatial autocorrelation in evaluating model performance. Quat. Sci. Rev., 24, 2173-2179.

Temming, A., Floeter, J. and Ehrich, S. (2007) Predation hot spots: large-scale impact of local aggregations. Ecosystems, 10, 865-876. 
Thomson, J.R., Mac Nally, R., Fleishman, E. and Horrocks, G. (2007) Predicting bird species distributions in reconstructed landscapes. Conserv. Biol., 21, 752-766.

Thuiller, W. (2003) BIOMOD - optimizing predictions of species distributions and projecting potential future shifts under global change. Glob. Change Biol., 9, 1353-1362.

Thuiller, W., Albert, C., Ara jo, M.B., Berry, P.M., Cabeza, M., Guisan, A., Hickler, T., Midgley, G.F., Paterson, J., Schurr, F.M., Sykes, M.T. and Zimmermann, N.E. (2008) Predicting global change impacts on plant species' distributions: Future challenges. Perspectives in Plant Ecology, Evolution and Systematics, 9, 137-152.

Tilman, D. and Kareiva, P. (1997) Spatial Ecology : the role of space in population dynamics and interspecific interactions. Columbia and Princeton: University Presses of California, 416pp.

Tregenza, T. (1995) Building on the ideal free distribution. Adv. Ecol. Res., 26, 253-307.

Tyler, J.A. and Gilliam, J.F. (1995) Ideal free distributions of stream fish: a model and test with minnows, Rhinicthys atratulus. Ecology, 76, 580-592.

Tyler, J.A. and Hargrove, W.W. (1997) Predicting spatial distribution of foragers over large resource landscapes: a modeling analysis of the ideal free distribution. Oikos, 79, 376-386.

Usio, N. (2007) Endangered crayfish in northern Japan: Distribution, abundance and microhabitat specificity in relation to stream and riparian environment. Biol. Conserv., 134, 517-526.

van der Ploeg, R.R., Bohm, W. and Kirkham, M.B. (1999) On the origin of the theory of mineral nutrition of plants and the law of the minimum. Soil Sci. Soc. Am. J., 63, 1055-1062.

Vaughan, I.P. and Ormerod, S.J. (2005) The continuing challenges of testing species distribution models. J. Appl. Ecol., 42, 720-730.

Vaz, S., Martin, C.S., Eastwood, P.D., Ernande, B., Carpentier, A., Meaden, G.J. and Coppin, F. (2008) Modelling species distributions using regression quantiles. J. Appl. Ecol., 45, 204-217.

Walters, C.J., Pauly, D. and Christensen, V. (1999) Ecospace: prediction of mesoscale spatial patterns in trophic relationships of exploited ecosystems, with emphasis on the impacts of marine protected areas. Ecosystems, 2, 539-554.

Ward, T.M., Hoedt, F., McLeay, L., Dimmlich, W.F., Jackson, G., Rogers, P.J. and Jones, K. (2001) Have recent mass mortalities of the sardine Sardinops sagax facilitated an expansion in the distribution and abundance of the anchovy Engraulis australis in South Australia? Mar. Ecol. Prog. Ser., 220, 241-251.

Werner, E.E. and Gilliam, J.F. (1984) The ontogenetic niche and species interactions in size-structured populations. Ann. Rev. Ecol. Syst., 15, 393-425.

Whittingham, M.J., Stephens, P.A., Bradbury, R.B. and Freckleton, R.P. (2006) Why do we still use stepwise modelling in ecology and behaviour? J. Anim. Ecol., 75, 1182-1189.

Wieland, K. and Jarre-Teichmann, A. (1997) Prediction of vertical distribution and ambient development temperature of Baltic cod, Gadus morhua L., eggs. Fish. Oceanogr., 6, 172-187.

Wintle, B.A. and Bardos, D.C. (2006) Modeling species-habitat relationships with spatially autocorrelated observation data. Ecol. Appl., 16, 1945-1958.

1045 Wood, S.N. (2006) Generalized additive models: an introduction with R. Boca Raton, Florida: Chapman and Hall, CRC Press, 392pp.

Zurell, D., Jeltsch, F., Dormann, C.F. and Schröder, B. (2009) Static species distribution models in dynamically changing systems: how good can predicitions really be? Ecography, 32, 733-744. 


\section{Figure legend}

Figure 1. The main categories of controls of fish spatial distribution: geographical attachment, environmental conditions, density dependent habitat selection, spatial dependency, demographic structure, species interactions, and memory. Blue controls are not dependent on the state of the population whilst red controls are. Green control (memory) is dependent on the current and past state of the population. 


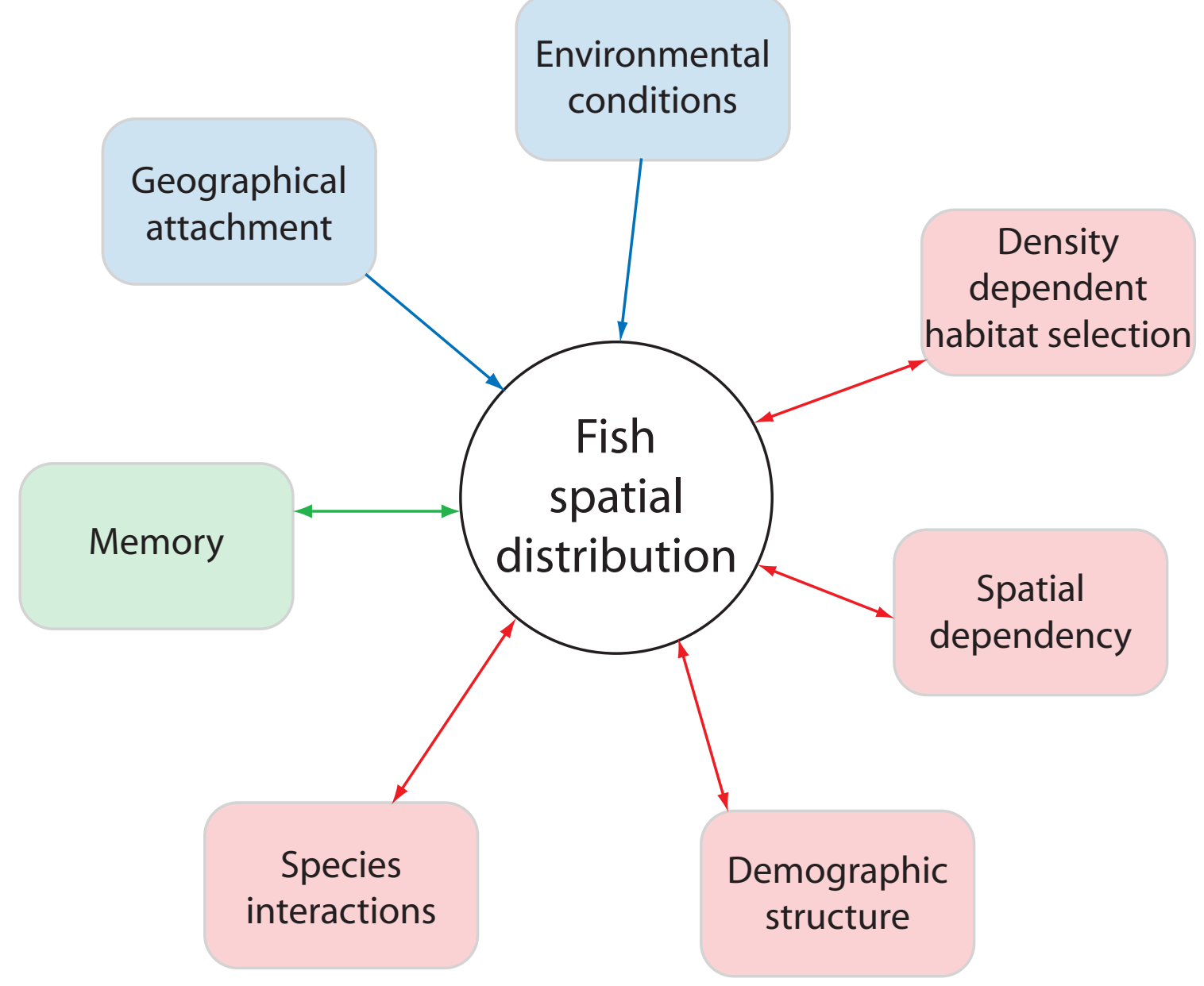

